\title{
Estrogen and progesterone receptor expression in breast carcinoma
}

\author{
Pathak TB ${ }^{1}$, Bashyal $\mathrm{R}^{1}$, Pun $\mathrm{CB}^{1}$, Shrestha $\mathrm{S}^{1}$, Bastola $\mathrm{S}^{1}$, Neupane $\mathrm{S}^{1}$, Poudel BR ${ }^{2}$, \\ Lee $\mathrm{MC}^{1}$
}

${ }^{1}$ Department of Pathology, BP Koirala Memorial Cancer Hospital, Bharatpur, Nepal

${ }^{2}$ Department of surgery, BP Koirala Memorial Cancer Hospital, Bharatpur, Nepal

\section{Keywords: \\ Breast carcinoma; \\ Estrogen receptor; \\ Progesterone receptor}

\begin{abstract}
Background: Breast carcinoma is the most common malignancy diagnosed among women worldwide and second leading cause of cancer mortality. One of the hallmarks of the disease is expression of estrogen receptor and progesterone receptor that ultimately drives prognosis and treatment modalities of the patient. The objective of this study was to determine the Estrogen and Progesterone receptor status in relation to histological grade of tumor.
\end{abstract}

Materials and Methods: This was an observational study, carried out in the department of Pathology, BP Koirala Memorial cancer Hospital, Bharatpur, from January 2010 to December 2010. A total of 136 patients with histological proven diagnosis of breast carcinoma was included in this study. These cases were graded according to the modified Bloom and Richardson criteria into three histological grades. We used immunohistochemistry to evaluate the expression of Estrogen and Progesterone in relation to histological grade of tumor.

Results: Out of 136 cases, there were $131(96 \%)$ cases of infiltrating ductal carcinoma with mean age of 48 years. Majority of cases were grade II (59\%) followed by grade III $(21 \%)$ and grade I (20\%). Estrogen Receptor and Progesterone Receptor expression were seen in 28\% and 19\% respectively. In grade I, $16(59 \%)$ and 10 (37\%) cases out of 27 were Estrogen Receptor and Progesterone Receptor positive respectively. In grade II, 21 (26\%) and 15(19\%) out of 80 cases were Estrogen Receptor and Progesterone Receptor positive respectively. In grade III, 1(3\%) and $1(3 \%)$ cases were positive for Estrogen Receptor and Progesterone Receptor respectively.

Conclusions: Expression of estrogen and progesterone is comparable to west with Estrogen and Progesterone showing inverse association with histological grades of tumor.

\section{INTRODUCTION}

Breast carcinoma is the most common malignancy diagnosed among women worldwide and the second leading

\section{Correspondence:}

Dr. Tilak Bahadur Pathak, MD

Department of Pathology, BP Koirala Memorial Cancer Hospital, Bharatpur, Nepal.

Email:pathaktilak@hotmail.com cause of cancer mortality. ${ }^{1}$ It accounts for $22 \%$ of all female cancers, which is more than twice the prevalence of cancer in women at any other sites. ${ }^{2}$ According to data from the cancer registry, breast cancer is the third common cancer in BP Koirala Memorial Cancer Hospital (BPKHCH) among the cancer patient visited in this hospital. Prognosis and management of breast cancer are influenced by the classic variables such as histological type and grade, tumor size, 
lymph node status, status of hormonal receptors- estrogen receptor (ER) and Progesterone receptor (PR) of tumor and more recently, HER-2/ neu (c-erbB-2) oncoprotein overexpression. $^{3}$ Medical therapeutic developments highlight the increasing importance of these prognostic and predictive factors. ${ }^{4}$

ER and PR receptors have increasing importance in the management of the breast malignancy. With established positive correlation of ER and PR with degree of tumor differentiation, determination of ER and PR status on biopsy specimen prior to therapeutic intervention is advocated as standard practice. ${ }^{5}$ Estrogen is an important mitogen exerting its activity by binding to its receptor and found in $50-80 \%$ of breast cancers. Endocrine treatments are assigned to antagonize the effects of estrogen. Therapeutic hormones like Tamoxifen competitively block ER thus antagonizing transcriptional activation of genes required for tumor growth. ${ }^{6}$ The presence of hormone receptors in the tumor tissue correlate well with the response to hormone therapy and chemotherapy. ${ }^{7}$ Studies have shown that 55$60 \%$ of women with ER positive tumors respond to additive or ablative hormone therapy, compared with about $8 \%$ of women with ER- negative tumors. Tumors that are better differentiated are more likely to be ER and PR positive and have a relatively better prognosis. Survival and response to hormone therapy are most favorable among women with tumor positive for both ER and PR, intermediate for tumors discordant on receptor status, and least favorable for tumors negative for both. ${ }^{8}$

One of the hallmarks of the disease is expression of ER and PR that ultimately drives prognosis and treatment modalities of the patient. The objective of this study was to determine the ER and PR status in breast carcinoma in relation to histological grade of tumor.

\section{MATERIALS AND METHODS}

This was an observational study carried out in the department

Table 1: ER status in relation to histological grade of tumor

\begin{tabular}{cccc}
\hline $\begin{array}{c}\text { Grade of } \\
\text { tumor }\end{array}$ & $\begin{array}{c}\text { No. of cases } \\
\mathbf{( \% )}\end{array}$ & $\begin{array}{c}\text { ER positive } \\
\text { frequency (\%) }\end{array}$ & $\begin{array}{c}\text { ER negative } \\
\text { frequency (\%) }\end{array}$ \\
\hline I & $27(19.9)$ & $16(59.3)$ & $11(40.0)$ \\
\hline II & $80(58.8)$ & $21(26.3)$ & $59(73.8)$ \\
\hline III & $29(21.3)$ & $1(3.4)$ & $28(96.6)$ \\
\hline
\end{tabular}

Table 2: PR status in relation to histological grade of tumor

\begin{tabular}{cccc}
\hline $\begin{array}{c}\text { Grade of } \\
\text { tumor }\end{array}$ & $\begin{array}{c}\text { No. of cases } \\
(\%)\end{array}$ & $\begin{array}{c}\text { PR positive } \\
\text { frequency (\%) }\end{array}$ & $\begin{array}{c}\text { PR negative } \\
\text { frequency (\%) }\end{array}$ \\
\hline I & $27(19.9)$ & $10(37.0)$ & $17(62.9)$ \\
II & $80(58.8)$ & $15(18.8)$ & $65(81.3)$ \\
III & $29(21.3)$ & $1(3.4)$ & $28(96.6)$ \\
\hline
\end{tabular}

of pathology, BPKMCH, Bharatpur, Chitwan. Samples of 136 patients with histological proven diagnosis of breast carcinoma from January 2010 to December 2010 were included in this study. All submitted tissue were routinely processed for Hematoxylin and eosin stain. ER / PR status was evaluted by immunohistochemistry technique with monoclonal antibodies (DAKO) using antigen-antibody Streptavidin immunoperoxidase technique; and other tumor related parameters were reported as per standards. ER and PR positivity was assessed using Allred Score system. The Allred score combines the percentage of positive cells and the intensity of the reaction product in the most of the carcinoma. The 2 scores are added together for a final score with 8 possible values. A simplified Allred score groups 0 and $2 ; 3$ and $4 ; 5$ and 6 ; and 7 and 8 for 4 possible values. ${ }^{9}$

\section{Proportion score (PS) ${ }^{9}$}

$\begin{array}{cl}\text { Score } & \text { \% of Positive cells } \\ 0 & 0 \\ 1 & <1 \\ 2 & 1-10 \\ 3 & 11-33 \\ 4 & 34-66 \\ 5 & 67-100\end{array}$

$\begin{array}{ll}\text { Intensity score } & \text { Intensity of positivity } \\ 0 & \text { None } \\ 1 & \text { Weak } \\ 2 & \text { Intermediate } \\ 3 & \text { Strong }\end{array}$

The proportion score and intensity score are added together for a total score.

$\begin{array}{ll}\text { Total score: PS+ IS } & \text { Interpretation } \\ 0,2 & \text { Negative } \\ 3,4,5,6,7,8 & \text { Positive. }\end{array}$

Elston- Ellis modification of Scarff- Bloom-Richardson grading system was used for histological grade. It evaluates the amount of tubule formation, the extend of nuclear pleomorphism and the mitotic count. Each variable is given a score of 1,2 , or 3 and the score are added to produce a grade. ${ }^{2}$ The mitotic score was determined by the number of mitotic figures found in 10 consecutive high- power fields (HPF) in the most mitotically active part of the tumor. Only clearly identifiable mitotic figures were counted.

\section{RESULTS}

One hundred and thirty six cases of breast carcinomas cases were tested for ER and PR status in relation to histological grading of tumor. The mean age was 48 years range from 21 to 80 years. The morphological categories were infiltrating ductal carcinoma, not otherwise specified (131 cases, 
$96 \%$ ) followed by medullary ( 2 cases, $1.4 \%$ ) carcinoma; mucinous carcinoma, infiltrating lobular carcinoma and infiltrating papillary carcinoma $1(0.7 \%)$ case each. The most frequent tumor grade was grade II (59\%) followed by grade III (21\%) and grade I (20\%).

ER and PR were positive in 38 (27.94\%) and 26 (19.11\%) cases respectively. ER positivity was observed in 16 (fig. 1A) grade I, 21 (26.25\%) grade II and 1 (3.44\%) grade III carcinoma (Table 1). Similarly PR positivity was observed in 10 (fig. 1B) grade I, 15 (18.75\%) grade II and 1 (3.44\%) grade III (Table 2). The ER and PR expression in infiltrating lobular carcinoma are shown in fig. 2. ER and PR expression in high grade tumors was significantly decreased compared to low grade tumor.

\section{DISCUSSION}

Breast cancer is a heterogeneous group of tumors and is the most common malignant tumor of the female malignancies. ${ }^{3,8}$ Ovarian steroid hormone are necessary for the normal development of the female breast and an imbalance precipitates neoplastic process. $^{5}$ Endocrine therapies are assigned to antagonize the effects of ER which is required for the transcriptional activation of the genes required for the tumor growth. The presence of hormone receptor in the tumor tissue correlates well with the response to hormone therapy and chemotherapy. ${ }^{10}$ The prognostic variables provide substantial information, which is useful in guiding the oncologist in determining the choice of treatment for the individual patient.

Prognosis of breast carcinoma has been associated with many variables like age, tumor size, tumor grade, histological type, lymph node status, and receptor status. All above mentioned variables have got prognostic significance but receptor status has been repeatedly proved to be one of the most important prognostic factors which have effect on five year survival rates and also mortality and disease free survival rates. ${ }^{11-15}$ It is well known that breast cancer patient whose breast cancer is positive for both ER and PR have best survival. ${ }^{10}$ The mean age at diagnosis in this study was
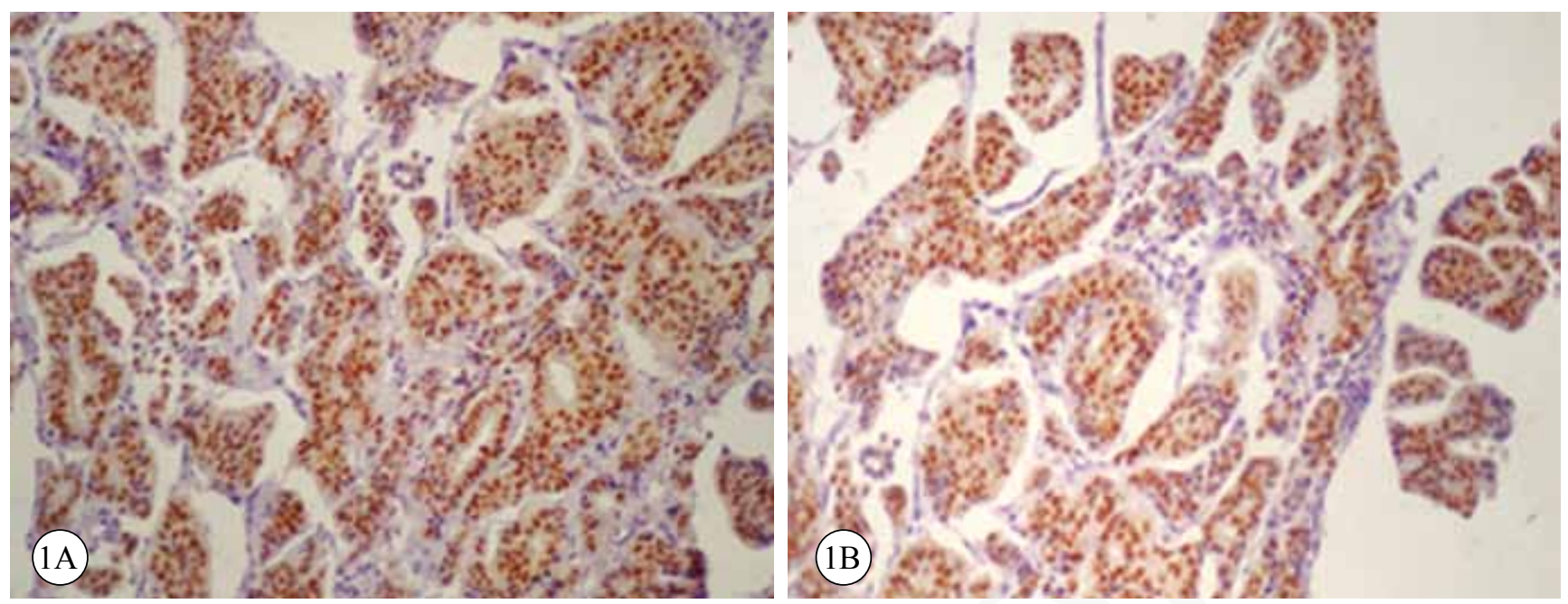

Figure 1A: Infiltrating ductal carcinoma showing ER Postivity (score: 8/8).

Figure 1B: Same tumor showing PR positivity (score: $8 / 8$ )
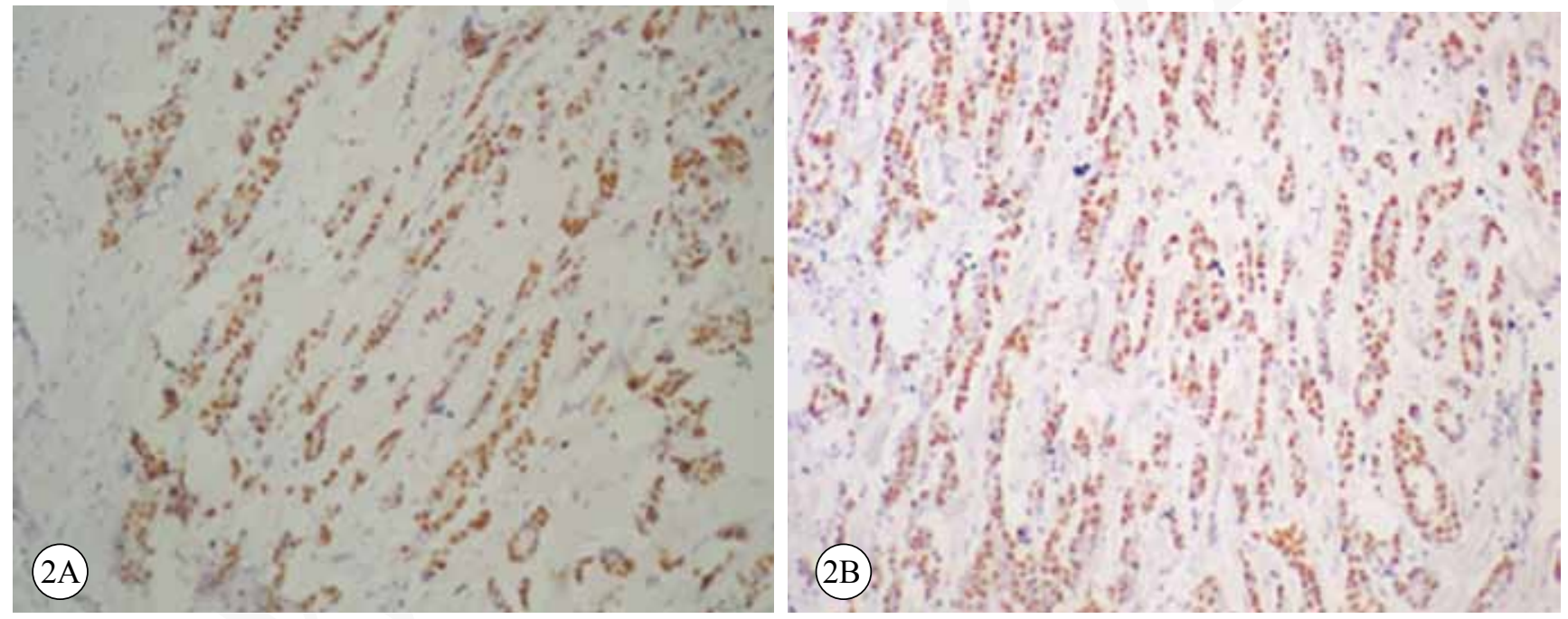

Figure 2A: Infiltrating lobular carcinoma showing ER Postivity (score: 8/8). Figure 2B: Same tumor showing PR positivity (score: 8/8) 
48 years which is a decade earlier than western study and other Asian countries including Pakistan, India, Thailand and Malayasia. ${ }^{11,16-18}$ The majority of patients were less than 50 years of age. Infiltrating ductal carcinoma was the most common histological type followed by Infiltrating lobular carcinoma, medullary carcinoma and papillary carcinoma in this study and other studies. ${ }^{13,14}$ Tumor grade is one of the prognostic factors in the breast cancer, tumors expressing higher grade tend to carry poor prognosis. In this study, grade II tumor constitute the highest number of cases at $59 \%$ followed by grade III and grade I. Similar findings were recorded in other studies in India, Pakistan, Thailand and Malyasia. ${ }^{11,16-18}$ Tumor grade is inversely proportional to the expression of ER and PR. In this study, expression of ER and PR was inversely associated with histological grade of tumor.

In the present study, overall positivity for ER was $28 \%$ while positivity for PR was 19\% which is comparable with Desai et $\mathrm{al}^{11}$ from India.

\section{CONCLUSION}

A significant association between different histological grade and ER / PR immunoreactivity was found. Expression of ER and PR is comparable to west with ER and PR showing inverse association with histological grades of tumor. Determination of ER and PR taken together may offer valuable prognostic information for clinical management of patients with breast carcinoma. A larger sample size study is needed in Nepalese population to corroborate the findings of this study.

\section{ACKNOWLEDGMENT}

I wish to express deep regards to Mr. M Sapkota, medical technologist for his immense help in technical support.

\section{REFERENCES}

1. Kamil M, Khalid I, Hashmin H, Biswas M, Kaur G, and Islam R. Association of carcinoma breast: Grade and estrogen and progesterone receptor expression. JCPSP 2010;20: 250-2.

2. Tavassoli FA, Devilee P. Pathology \& Genetics Tumos of the Breast and female Genital Organs. III series IARC press: Lyon 2003:10-21.

3. Sharif MA, Mamoon N, Mustaq S, Khadim MT. Morphological profile and association of HER-2/Neu with Prognostic markers in Breast carcinoma in Northern Pakistan. JCPSP 2009, 19: 99-103.

4. Almasri NM, Achmad M. Immunohistochemical evaluation of human epidermal growth factor receptor 2 and estrogen and progesterone receptors in breast carcinoma in Jordan. Breast cancer res 2005;7:598-604.

5. Nisa A, Bhurgri Y, R Farrukh, Kayani N. C of ER, PR \& HER-2/ neu (C-erb B2) reactivity pattern with histologic grade, tumor size and lymph node status in breast cancer. Asian Pac J Cancer Prev 2008;9:553-6.

6. Barnes DM, Hanby AM. Estrogen and progesterone receptors in breast cancer: Past, present \& future.Histopathology 2001;38:271-4.

7. Maynard PV, Davies CJ, Blamey RW, et al . Relationship between estrogen- receptor content and histological grade in human primary breast tumor. Br J Cancer 1978;38:745-8.

8. Lal P, Tan LK, Chen B. Correlation of HER-2 status with estrogen and progesterone receptors and histologic features in 3,655 invasive breast carcinoma. Am J Clin Pathol 2005;123:541-6.

9. Umemura S, Kurosumi M, Moriya $\mathrm{T}$ et al. Immunohistochemical evaluation for hormone receptors in breast cancer: a pratically useful evaluation system and handling protocol. Breast cancer 2006;1: 232235

10. Parise CA, Bauer KR, Brown MM, Caggiano V. Breast Cancer subtypes as defined by the estrogen receptor (Er), progesterone receptor (PR), and the human epidermal growth factor receptor 2 (HER 2) among women with invasive breast cancer in California 1999-2004. The breast journal 2009;15:593-602.

11. Desai SB, Moonim MT, Gill AK, Punia RS, Naresh KN, Chinoy RF. Hormone receptor status of breast cancer in India: a study of 798 tumors. Breast 2000;9:267-70.

12. Mamoon N, Hassan U, Mushtaq S. Breast carcinoma in young women aged 30 or less in Northern Pakistan- the Armed Forces Institute of pathology experience. Asian Pac J cancer 2009;10:1079-82.

13. Hall IJ, Moorman PG, Millikan RC, Newman B. Comparative analysis of breast cancer risk factors among African- Americal women and white women. Am J epidemol 2005;161:40-51.

14. Jatoi I, Anderson WF, Rao SR, Devesa SS. Breast cancer trends among black and white women in the United States. J clin Oncol 2005;23:7836-41.

15. Brinton LA, Sherman ME, Carreon JD, Anderson WF. Recent trends in breast cancer among younger women in the United States. J Natl Cancer Inst 2008;100:1643-8.

16. Malik IA, Mushtaq S, Khan AH, et al. A morphological study of 280 mastectomy specimen of breast carcinoma. Pak J Pathol 1994;5:5-8.

17. Siddiqui MS, Kayani N, Pervez $S$ et al. Breast Diseses: Histopathological analysis of 3279 cases at a tertiary care centre in Pakistan. J Pak Med Assoc 2003;53:94-107.

18. Aryandono T, Harijadi, Soeriptio. Hormone receptor status of operable breast cancers in Indonesia: correlation with other prognostic factors and survival. Asian Pac J cancer prev 2006;7:321-4. 